\title{
Instrumented assessment of motor function in dyskinetic cerebral palsy: a systematic review
}

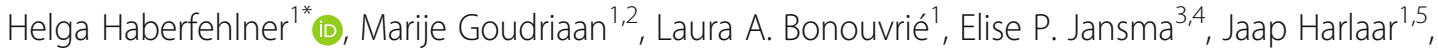

R. Jeroen Vermeulen ${ }^{6}$, Marjolein M. van der Krogt ${ }^{1}$ and Annemieke I. Buizer ${ }^{1}$

\begin{abstract}
Background: In this systematic review we investigate which instrumented measurements are available to assess motor impairments, related activity limitations and participation restrictions in children and young adults with dyskinetic cerebral palsy. We aim to classify these instrumented measurements using the categories of the international classification of functioning, disability and health for children and youth (ICF-CY) and provide an overview of the outcome parameters.
\end{abstract}

Methods: A systematic literature search was performed in November 2019. We electronically searched Pubmed, Embase and Scopus databases. Search blocks included (a) cerebral palsy, (b) athetosis, dystonia and/or dyskinesia, (c) age 2-24 years and (d) instrumented measurements (using keywords such as biomechanics, sensors, smartphone, and robot).

Results: Our search yielded 4537 articles. After inspection of titles and abstracts, a full text of 245 of those articles were included and assessed for further eligibility. A total of 49 articles met our inclusion criteria. A broad spectrum of instruments and technologies are used to assess motor function in dyskinetic cerebral palsy, with the majority using 3D motion capture and surface electromyography. Only for a small number of instruments methodological quality was assessed, with only one study showing an adequate assessment of test-retest reliability. The majority of studies was at ICF-CY function and structure level and assessed control of voluntary movement (29 of 49) mainly in the upper extremity, followed by assessment of involuntary movements (15 of 49), muscle tone/motor reflex (6 of 49), gait pattern (5 of 49) and muscle power (2 of 49). At ICF-CY level of activities and participation hand and arm use (9 of 49), fine hand use (5 of 49), lifting and carrying objects (3 of 49), maintaining a body position (2 of 49), walking (1 of 49) and moving around using equipment ( 1 of 49) was assessed. Only a few methods are potentially suitable outside the clinical environment (e.g. inertial sensors, accelerometers).

Conclusion: Although the current review shows the potential of several instrumented methods to be used as objective outcome measures in dyskinetic cerebral palsy, their methodological quality is still unknown. Future development should focus on evaluating clinimetrics, including validating against clinical meaningfulness. New technological developments should aim for measurements that can be applied outside the laboratory.

Keywords: Dystonia, Choreoathetosis, Technology, Reliability, Validity, Responsiveness, Quantitative assessment, Devices

\footnotetext{
* Correspondence: h.haberfehlner@amsterdamumc.nl

${ }^{1}$ Department of Rehabilitation Medicine, Amsterdam Movement Sciences,

Amsterdam UMC, PO Box 7057, Amsterdam 1007MB, The Netherlands

Full list of author information is available at the end of the article
}

(c) The Author(s). 2020 Open Access This article is distributed under the terms of the Creative Commons Attribution 4.0 International License (http://creativecommons.org/licenses/by/4.0/), which permits unrestricted use, distribution, and reproduction in any medium, provided you give appropriate credit to the original author(s) and the source, provide a link to the Creative Commons license, and indicate if changes were made. The Creative Commons Public Domain Dedication waiver (http://creativecommons.org/publicdomain/zero/1.0/) applies to the data made available in this article, unless otherwise stated. 


\section{Background}

Cerebral palsy (CP) is the most common physically disabling condition in childhood, with a prevalence of approximately two in every 1000 live births in Europe [1]. Dyskinetic CP accounts for 6-15\% of all children with CP and is the second most common form after spastic $\mathrm{CP}$ (85\%) [1-3]. A majority of children with dyskinetic CP have a lesion in the basal ganglia and thalamus or both [4]. Children and young adults with dyskinetic CP experience limitations in mobility and manual ability due to motor impairments. These motor impairments are characterized by involuntary movements and changes in muscle tone (i.e. dystonia and choreoathetosis) [2, 5]. The severity of motor impairments and limitations in mobility and manual ability is wide-ranging in dyskinetic CP. However, the majority of children with dyskinetic CP are severely affected, with about 70-80\% classified within the Gross Motor Functioning Classification System (GMFCS) [6] level IV-V (i.e. non-ambulatory) and the Manual Ability Classification System (MACS) [7] level IV-V (i.e. severely impaired manual ability) $[8,9]$.

Several scales are currently used to describe the severity of dystonia in dyskinetic CP [10]. Examples are the Barry-Albright Dystonia Scale (BADS) [11], Dyskinesia Impairment Scale (DIS) [12], Burke-Fahn-Marsden Dystonia Rating Scale (BFMDRS) [13], Hypertonia Assessment Tool (HAT) [14, 15], and Unified Dystonia Rating Scale (UDRS) [16]. The DIS in addition to dystonia also assesses choreoathetosis [12]. Clinical scales are often combined with questionnaires such as the Pediatric Evaluation of Disability Inventory (PEDI) [17] and Child Health Index of Life with Disabilities (CPCHILD) [18], and performance based outcome measures such as Quality of Upper Extremity Skills Test (QUEST) [19]. Also individualized outcome measures (Goal attainment scaling (GAS) [20] or Canadian Occupational Performance Measure (COPM) [21] are used to evaluate treatment outcome in dyskinetic CP [22-26].

The current clinical scales (e.g. BADS, DIS and BFMDRS) are based on the observation by a clinician [10]. Although treatment (e.g. intrathecal baclofen and deep brain stimulation) targets a decrease of dystonia and choreoathetosis the effects of treatment have mainly been found on individualized outcome measures (e.g. GAS and COPM) and less or not at all on clinical scales [27, 28]. Outcomes of the clinical scales measuring dystonia and choreoathetosis are subjective, i.e. dependent on the personal judgement and experience of the rater. Therefore, it might be useful to measure motor impairments in this patient group using objective measurements.

Another reason for the discrepancy in outcome between clinical scales and individualized outcome measures might be that the severity of abnormal movements varies over time and is exacerbated by external stimuli, such as stress, pain and noise [4], therefore improvement in dystonia and choreoathetosis might be difficult to capture at one time point in the clinical environment. Ideally, measuring at home might result in more meaningful and precise outcome.

Kinematic measures within a laboratory environment (i.e. gait and upper limb functional analysis) are frequently performed within a general population of $\mathrm{CP}$ and seem to become more common in dyskinetic CP as well [29]. Devices such as surface electromyography (sEMG) and wearable sensors may offer additional opportunities to objectively quantity dyskinetic movements (i.e. as functions of the musculoskeletal system) such as dystonia and choreoathetosis in dyskinetic CP. Wearable sensors may also allow for assessment of activities and participation outside the laboratory environment.

Although these techniques are promising, there is currently no consensus which outcome parameters are relevant in the assessment of dyskinetic movements or related activity limitations and participation restrictions in dyskinetic CP. As a first step we deem it necessary to inventory the outcome parameters that are currently used in studies using instrumented measures of motor function. To describe functioning in dyskinetic cerebral palsy, the ICF (international classification of functioning) provides a useful framework [30]. It can be used to classify assessment tools as to which aspect of functioning they measure [30]. The ICF is a classification system of functioning and disability, distinguishing between (a) body function and structure, (b) activities and participation, and (c) components of contextual factors i.e. environmental factors and personal factors [31]. We considered the following chapters of the ICF to be relevant for the assessment of motor function in dyskinetic CP: (a) within body function and structure: Neuromusculoskeletal and movement-related functions, focusing on muscle and movement functions and (b) within activities and participation: Mobility, especially changing and maintaining body position, carrying, moving and handling objects and walking and moving. The ICF children and youth version (ICF-CY) has derived from the ICF expanding the coverage of the main ICF volume by providing specific content and additional detail to more fully cover the body functions and structures, activities and participation, and environments of particular relevance to infants, toddlers, children and adolescents [31]. We choose to use the ICF-CY categories to cover the age range from preschool children up to young adults. See Table 1 for codes and definitions of ICF-CY [31].

\section{Aim of review}

The objective of this review is to investigate which instrumented measurements are available at all levels of the ICF-CY to assess motor function in children and 
Table 1 Considered relevant categories of the international classification of functioning, disability and health for children and youth (ICF-CY) [31] for dyskinetic cerebral palsy related to movement disorders

\begin{tabular}{|c|c|c|c|c|c|c|c|}
\hline \multicolumn{8}{|c|}{ Body function and structure } \\
\hline \multicolumn{8}{|c|}{ Neuromusculoskeletal and movement-related functions (Chapter 7) } \\
\hline \multicolumn{4}{|c|}{ Muscle functions (b730-b749) } & \multicolumn{4}{|c|}{ Movement functions (b750-b789) } \\
\hline b730 & b735 & b740 & b750 & b755 & b760 & b765 & b770 \\
\hline $\begin{array}{l}\text { Muscle } \\
\text { power }^{\mathrm{a}}\end{array}$ & Muscle tone & $\begin{array}{l}\text { Muscle } \\
\text { endurance }\end{array}$ & Motor reflex & $\begin{array}{l}\text { Involuntary } \\
\text { movement } \\
\text { reaction }\end{array}$ & $\begin{array}{l}\text { Control of } \\
\text { voluntary } \\
\text { movement }\end{array}$ & $\begin{array}{l}\text { Involuntary } \\
\text { movement }\end{array}$ & Gait pattern \\
\hline $\begin{array}{l}\text { Function } \\
\text { related to } \\
\text { the force } \\
\text { generated } \\
\text { by the } \\
\text { contraction } \\
\text { of a muscle } \\
\text { or muscle } \\
\text { group. }\end{array}$ & $\begin{array}{l}\text { Functions related } \\
\text { to the tension } \\
\text { present in the } \\
\text { resting muscles } \\
\text { and the resistance } \\
\text { offered when } \\
\text { trying to move the } \\
\text { muscles passivelyc. }\end{array}$ & $\begin{array}{l}\text { Functions } \\
\text { related to } \\
\text { sustaining } \\
\text { muscle } \\
\text { contraction } \\
\text { for the } \\
\text { required } \\
\text { period of } \\
\text { timed. }\end{array}$ & $\begin{array}{l}\text { Functions of } \\
\text { involuntary } \\
\text { contraction of } \\
\text { muscles automatic- } \\
\text { ally induced by } \\
\text { specific stimulie. }\end{array}$ & $\begin{array}{l}\text { Functions of } \\
\text { involuntary } \\
\text { contractions of } \\
\text { large muscles or } \\
\text { the whole body } \\
\text { induced by body } \\
\text { position, balance } \\
\text { and threatening } \\
\text { stimulif. }\end{array}$ & $\begin{array}{l}\text { Functions } \\
\text { associated } \\
\text { with control } \\
\text { over and } \\
\text { coordination } \\
\text { of voluntary } \\
\text { movements }\end{array}$ & $\begin{array}{l}\text { Functions of } \\
\text { unintentional, } \\
\text { non- or semi- } \\
\text { purposive invol- } \\
\text { untary contrac- } \\
\text { tions of a } \\
\text { muscle or } \\
\text { group of } \\
\text { musclesh. }\end{array}$ & $\begin{array}{l}\text { Functions of } \\
\text { movement patterns } \\
\text { associated with } \\
\text { walking, running or } \\
\text { other whole body } \\
\text { movements.' }\end{array}$ \\
\hline
\end{tabular}

Activities and participation

Mobility (Chapter 4) position (d410-d429)

\begin{tabular}{|c|c|c|c|c|c|c|c|}
\hline$d 410$ & $d 415$ & $d 430$ & d440 & d445 & $d 450$ & $d 455$ & $d 465$ \\
\hline $\begin{array}{l}\text { Changing } \\
\text { basic body } \\
\text { position }\end{array}$ & $\begin{array}{l}\text { Maintaining a body } \\
\text { position }\end{array}$ & $\begin{array}{l}\text { Lifting and } \\
\text { carrying } \\
\text { objects }\end{array}$ & Fine hand use & Hand and arm use & Walking & Moving around & $\begin{array}{l}\text { Moving around using } \\
\text { equipment }\end{array}$ \\
\hline $\begin{array}{l}\text { Getting into } \\
\text { and out of a } \\
\text { body } \\
\text { position and } \\
\text { moving from } \\
\text { one location } \\
\text { to another. }\end{array}$ & $\begin{array}{l}\text { Staying in the same } \\
\text { body position as } \\
\text { required. }\end{array}$ & $\begin{array}{l}\text { Raising up } \\
\text { an object or } \\
\text { taking } \\
\text { something } \\
\text { from one } \\
\text { place to } \\
\text { another. }\end{array}$ & $\begin{array}{l}\text { Performing the } \\
\text { coordinated actions } \\
\text { of handling objects, } \\
\text { picking up, } \\
\text { manipulating and } \\
\text { releasing them } \\
\text { using one's hand, } \\
\text { fingers and thumb. }\end{array}$ & $\begin{array}{l}\text { Performing the } \\
\text { coordinated } \\
\text { actions required to } \\
\text { move objects or to } \\
\text { manipulate them } \\
\text { by using hands } \\
\text { and arms. }\end{array}$ & $\begin{array}{l}\text { Moving } \\
\text { along a } \\
\text { surface on } \\
\text { foot, step by } \\
\text { step, so that } \\
\text { one foot is } \\
\text { always on } \\
\text { the ground. }\end{array}$ & $\begin{array}{l}\text { Moving the } \\
\text { whole body } \\
\text { from one place } \\
\text { to another by } \\
\text { means other } \\
\text { than walking. }\end{array}$ & $\begin{array}{l}\text { Moving the whole } \\
\text { body from place to } \\
\text { place, on any surface } \\
\text { or space, by using } \\
\text { specific devices } \\
\text { designed to facilitate } \\
\text { moving or create } \\
\text { other ways of } \\
\text { moving around. }\end{array}$ \\
\hline
\end{tabular}

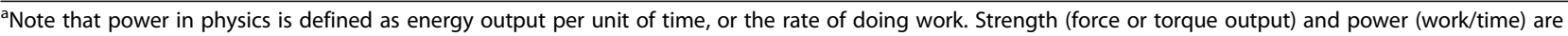
separate physical parameters. However, the ICF-CY does not distinguish between strength and power. Therefore articles measuring strength were included in the category muscle power

Inclusion:

${ }^{b}$ Functions associated with the power of specific muscles and muscle groups, muscles of one limb, one side of the body, the lower half of the body, all limbs, the trunk and the body as a whole

'Functions associated with the tension of isolated muscles and muscle groups, muscles of one limb, one side of the body and the lower half of the body, muscles of all limbs, muscles of the trunk, and all muscles of the body; impairments such as hypotonia, hypertonia and muscle spasticity

${ }^{\mathrm{d} F u n c t i o n s}$ associated with sustaining muscle contraction for isolated muscles and muscle groups, and all muscles of the body

${ }^{e}$ Functions of stretch motor reflex, automatic local joint reflex, reflexes generated by noxious stimuli and other exteroceptive stimuli; withdrawal reflex, biceps reflex, radius reflex, quadriceps reflex, patellar reflex, ankle reflex, appearance and persistence of reflexes

${ }^{\mathrm{f}}$ Functions of postural reactions, righting reactions, body adjustment reactions, balance reactions, supporting reactions, defensive reactions

${ }^{9}$ Functions of control of simple voluntary movements and of complex voluntary movements, coordination of voluntary movements, supportive functions of arm or leg, right left motor coordination, eye hand coordination, eye foot coordination; impairments such as control and coordination problems

${ }^{h}$ Functions of involuntary contractions of muscles; impairments such as tremors, tics, mannerisms, stereotypies, motor perseveration, chorea, athetosis, vocal tics, dystonic movements and dyskinesia

'Walking patterns and running patterns

young adults with dyskinetic CP. Additionally, we aim to provide an overview of the parameters that can be extracted from these instrumented measurements.

\section{Methods}

\section{Search and selection}

A literature search was performed in November 2019. We electronically searched: Pubmed, Embase and Scopus. The search strategy for Pubmed has been published along with the study protocol [32]. For the other databases the same search strategy was used, but modified to the corresponding database. The searches are provided in the supplementary materials (Additional file 1). In brief, the search blocks included (a) diagnosis (i.e. cerebral palsy), (b) movement disorder (i.e. dyskinesia, athetosis and dystonia), (c) age (i.e. 2-24 years) and (d) instrumented measurements with 
keywords such as biomechanics, accelerometer, velocity, speed, electromyography, sensors, smart phone, computer, and robot. To also cover literature where cerebral palsy was not mentioned in the title or abstract, population was defined by: (a) and (b) or (b) and (c).

The search results were imported into Endnote X8 (Clarivate Analytics, Boston, USA). After removal of duplicates, all titles and abstracts were transferred to Rayyan (Qatar Computing Research Institute, Qatar), a free web application for systematic reviews [33]. In Rayyan two reviewers (HH, MG) independently screened titles and abstracts against the inclusion criteria. The inclusion criteria are presented in Table 2. The studies that were selected by $\mathrm{HH}$ and MG were retrieved in full text and their citation information imported in Endnote as a second database. The reference lists of all studies retrieved in full text as well relevant secondary research (i.e. reviews) were screened for additional studies. The full text of selected citations were then assessed in detail against the same inclusion criteria defined in the PICOS (Participants, Intervention, Comparison, Outcome, and Study design) framework [34] (Table 2) by both reviewers (HH, MG). Any disagreements that occurred between these reviewers at each stage of the study selection process was resolved through discussion with a third and if necessary fourth reviewer (LB, AB).
Data extraction and assessment of methodological quality We extracted relevant information from each included paper in a custom-made Excel based (Microsoft Office, Microsoft, Redmond, WA, USA) data extraction form. Information regarding patient characteristics, assessed ICFCY categories (Table 1), body region, outcome parameters, used instruments/technologies/software, and primary aim of the study was extracted. Studies may be categorized in more than one ICF-CY category when multiple experiments are performed or an experiment includes outcome parameters in different categories. Measurement properties of the available techniques (i.e. validity, reliability, responsiveness and measurement error) were assessed with the COnsensus-based Standards for the selection of health Measurement INstruments (COSMIN) checklist of bias [35]. Data extraction was done by one reviewer $(\mathrm{HH})$ and audited by a second reviewer (MG).

\section{Results}

An overview of the search and selection process is shown in Fig. 1 using a Preferred Reporting Items for Systematic Reviews and Meta-analyses (PRISMA) flow diagram [34].

After removal of duplicates, our search yielded 4537 records, of which a total of 245 were included in full-text for further eligibility assessment. Subsequently, 196 articles were excluded based on the following main reasons: 1) no

Table 2 Inclusion and exclusion criteria defined in the PICOS (Participants, Intervention, Comparison, Outcome, Study design) framework

\begin{tabular}{|c|c|c|}
\hline & Description & Inclusion/Exclusion criteria \\
\hline Participants & Dyskinetic CP, 2-24 years & $\begin{array}{l}\text {-The study sample or an substantial number of subjects } \\
\text { (minimal 50\%) are represented in the study population } \\
\text { or in a sub-study population that is separately analyzed } \\
\text {-As definition of dyskinetic CP is not always clear also } \\
\text { studies describing dystonia due to CP are included }\end{array}$ \\
\hline Intervention & $\begin{array}{l}\text { Instrumented measurements to assess } \\
\text { movement function and related } \\
\text { activities/participation }\end{array}$ & $\begin{array}{l}\text {-Imaging techniques (e.g. MRI) were excluded } \\
\text {-Studies that only use video recording without } \\
\text { computerized analyzing techniques but purely } \\
\text { to score from the video through observation } \\
\text { were excluded. }\end{array}$ \\
\hline
\end{tabular}

Comparison No control group or comparison is required

-Comparison to a clinical test, a control group or the effect of intervention assessed by the methods will be reported but if there is none, the method is still listed in the review

Outcome

Study design
Outcomes measured in one of the ICF-CY level reported in Table 1 (i.e. muscle or movement function, changing and maintaining body position, carrying, moving and handling objects, (fine) hand and arm use or walking and moving with or without equipment)

Original research studies are included, peer reviewed full text and conference abstracts with sufficient information on used methodology and participants
-Other categories of ICF-CY (e.g. mental functions, sensory functions and pain, speech, communication or self-care) were excluded 


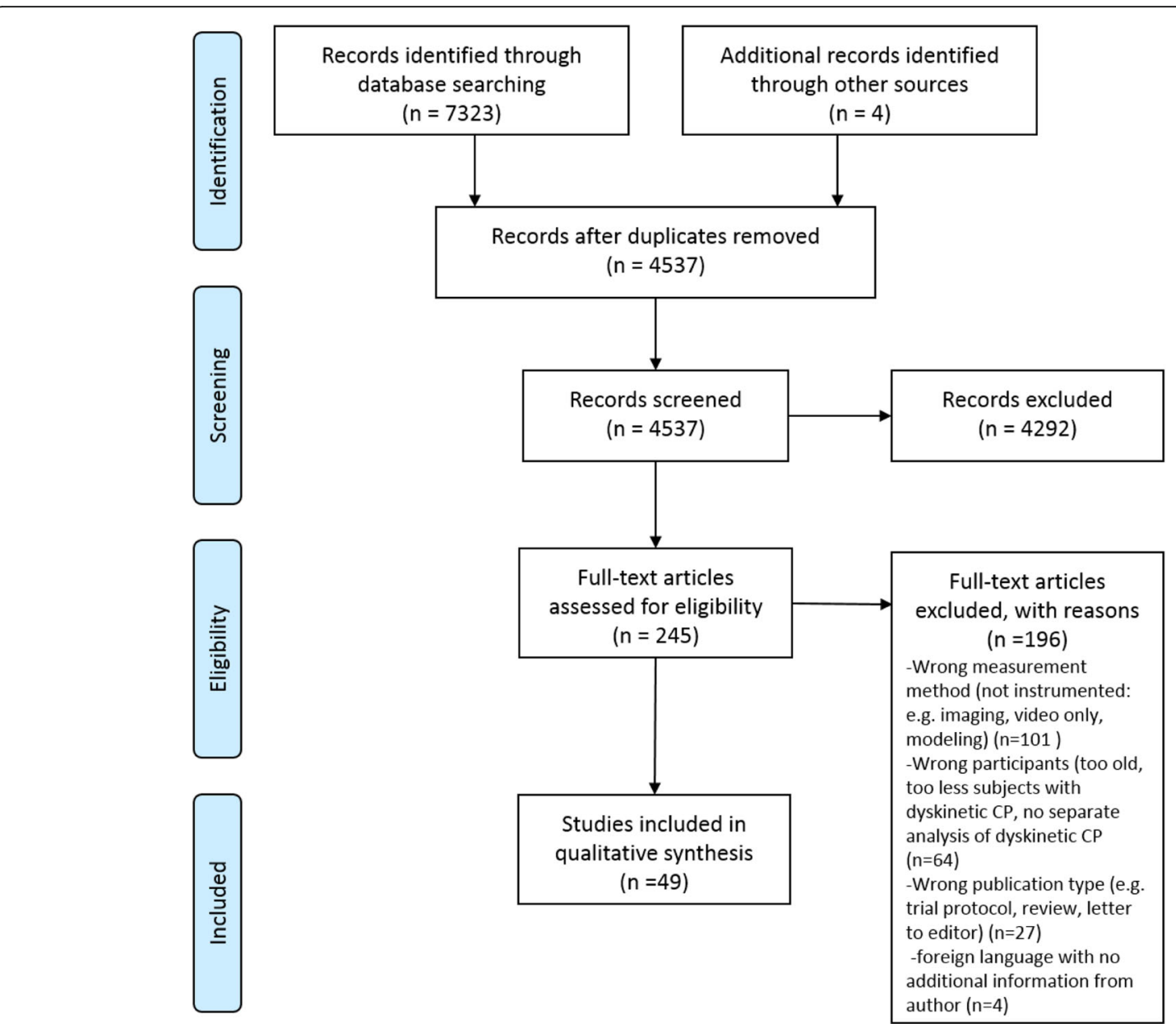

Fig. 1 PRISMA flow diagram for information through the different phases of study selection

instrumented measurements were used to assess movement function, 2) the participants were too old, 3) too many participants did not have the diagnosis of dyskinetic $\mathrm{CP}$, or 4) in case of mixed group of participants with $\mathrm{CP}$, no sub analysis of dyskinetic group was performed. Finally, 49 articles [36-84] were included in the review. A summary of the included studies is provided as supplementary material (Additional file 2). Overall the sample size of the included studies was low with majority of studies including 10-20 participants. Figure 2 shows an overview of frequency of the ICF-CY categories and frequency of used instruments and technologies.

\section{Body function and structures Muscle functions}

Muscle power Torques and force levels were assessed by force sensors in the lower [38] and upper extremity [45]. In the lower extremity, maximum isometric flexion and extension torques of the knee [38] were analyzed. In the upper extremity, force variability as well as change of force variability with increased force levels of the biceps were studied [45].

From a biomechanical point of view strength (force or torque output) and power (work/time) are separate physical parameters. However, the ICF-CY does not distinguish between strength and power. Therefore articles measuring torque or force were included in the category muscle power.

Muscle tone / motor reflex Muscle tone and motor reflex were measured in both upper and lower extremity, more specifically at elbow $[44,46,51]$, knee $[36-38]$ and ankle [37]. The most frequently used method was sEMG alone or combined with force sensors or position measures [36-38, 44, 46, 51]. These measurements intended to distinguish between spastic and dyskinetic CP [36-38, 51 ], to determine the relation of muscle tone and motor reflex in dyskinetic $\mathrm{CP}$ [46], and/or the influence of muscle tone and motor reflex on control of voluntary movement $[44,51]$. 


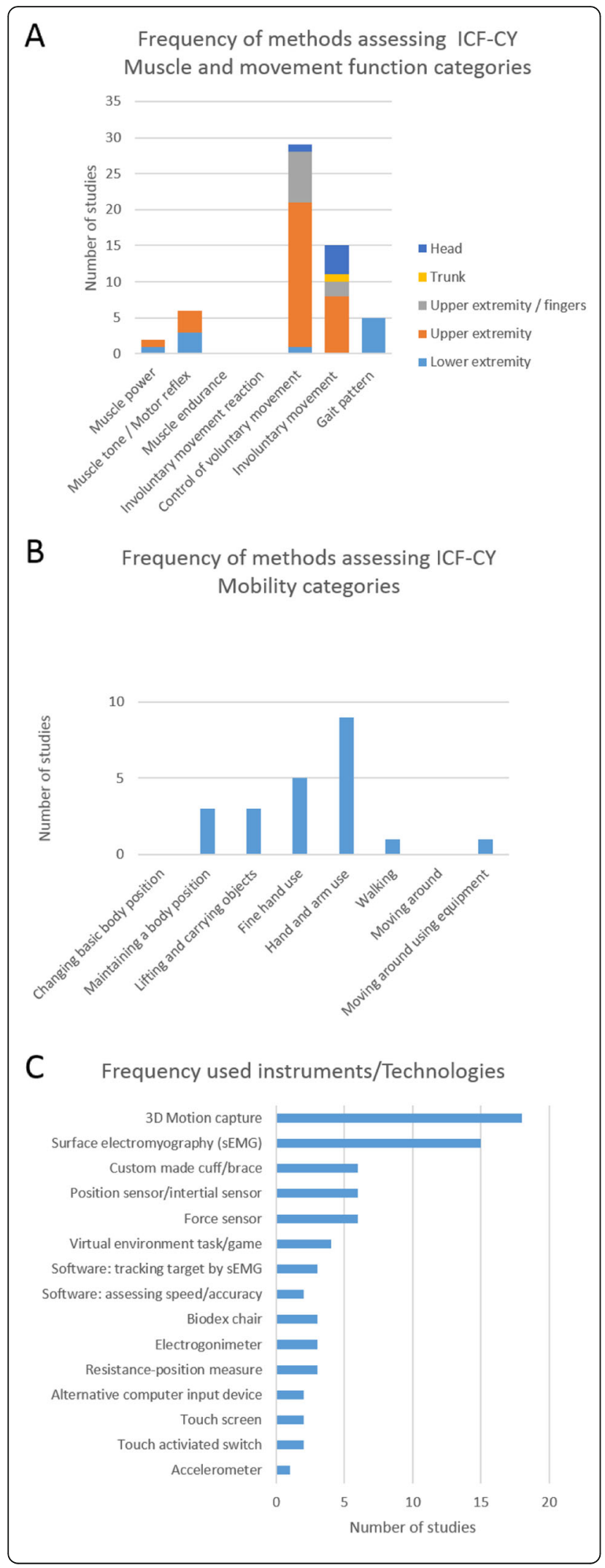

Fig. 2 Frequency of instrumented assessed categories within the international classification of functioning, disability and health for children and youth (ICF-CY) for dyskinetic cerebral palsy a: Muscle and movement functions categories, $\mathbf{b}$ : Mobility categories and $\mathbf{c}$ : Frequency of used instruments and technologies

\section{Movement functions}

Involuntary movement Involuntary movement was mainly quantified by determining the overflow of muscle activation that is not directly required for a task, thus resulting in involuntary movement. This was mostly measured as kinematic overflow by 3D motion analysis [51, 54, 60,61] and overflow of muscle activation by sEMG [44, 71-74]. Different stimuli were used to trigger overflow e.g. movement of contralateral arm, hand, fingers, antagonist muscles [44, 51, 54, 60, 61, 71, 73, 74], and eye-blinking [61]. Other studies measured the involuntary movement component during voluntary movements [48, 82], while holding the arm in a raised position and during lying in rest [62]. In addition, movement parameters were measured during quiet sitting using perturbations as a sudden noise [80], closing the eyes [83] or computer use [84].

Control of voluntary movement Control of voluntary movement was measured for the upper extremity [43, $44,47-60,63-67,78,79]$, for the fingers [69-77], for the lower extremity [43], head [81] and trunk [78, 79] in a variety of ways:

(a) Position and joint angle measurements were performed using 3D motion tracking and other measures like electrogoniometry and shape tape to assess spatiotemporal and kinematic parameters during different upper extremity tasks $[48,51-56,58-60,63,75,76,78$, 79] (Additional file 7). Thorax position and stability of the trunk during reaching was assessed in two studies [78, 79] (Additional file 7).

(b) Virtual reality games and touch screen tracking games were also used to evaluate voluntary movement function of upper extremity, finger, and head movements. Several input and output devices were used i.e. a manipulandum controlled by arm movement $[49,50]$, a touch screen tablet operated by the index finger $[69,70]$, a virtual handwriting system [77], touch activated switches [65-67] and different kind of mice [81]. These devices were used to assess a range of outcome parameters mainly studying movement time and/or accuracy (Additional file 7).

(c) Muscle activity was measured in several studies by sEMG to assess the contribution of muscle activity to task performance. This was done during elbow extension movements [44], during activating a switch by touch 
[65], during a finger-to-nose task [59] and during a 8figure writing task $[75,76]$.

(d) sEMG was also used to assess voluntary muscle activation to control tracking games on a (computer) screen e.g. tracking a target by activating biceps and triceps [47], keeping an indicator in a central position by biceps activation [43], control of position and movement of a line by left and right biceps activation [64] or tracking a target by isometrically activating intrinsic muscles [71-74].

Gait pattern Parameters to assess gait pattern were all measured by marker based 3D motion capture systems. The marker models used and parameters derived from it differed between studies, but consisted mainly of spatiotemporal and kinematic parameters [38-42] (Additional file 7).

\section{Activities and participation}

Control of voluntary and involuntary movement was assessed within functional activities in some studies and these studies were classified within the following categories of activities and participation with the ICF-CY: (a) maintaining a body position [79, 80, 83], (b) lifting and carrying objects $[52,53,55,56]$, (c) fine hand use [69, 70, 75-77]; (d) hand and arm use [51, 54, 57-60, 63, $65-67,78,79]$. One study measured not only gait pattern but also walking velocity and was therefore classified within the ICF-CY category (e) walking [38]. (f) Moving around using equipment (i.e. electric wheelchair) was assessed in one recent study [68]. No studies were found that assessed ICF-CY categories of changing basic body position and moving around.

\section{Assessment of methodological quality}

Initially we aimed to assess methodological quality using the COSMIN checklist [35] However, most papers did not have as primary aim to determine measurement properties and provided little to no information for a formal scoring of the measurement properties of described instrumented measurements. We therefore decided to give an indication concerning construct validity by (a) describing which parameters were compared to a clinical instrument (i.e. hypotheses testing, convergent validity) and (b) describing which parameters were used to compare a dyskinetic $\mathrm{CP}$ group to a control group or to distinguish between subgroups (e.g. between spastic and dyskinetic $\mathrm{CP}$, i.e. hypotheses testing, discriminative validity) (Additional file 7 ). We also extracted information on whether test-retest or intra-session reliability was assessed and/or if information on the measurement error was available (Additional file 7). An indication of responsiveness of the used instrumented methods is given by describing if the method has been used in evaluation of an intervention (Additional file 7).
The results of studies that report the correlation of measured parameters to a clinical comparator instrument (e.g. BADS, UDRS, BFMDRS, MACS) [39, 47, 51-53, 55, 56, 58-62, 69, 71-73] are summarized in Additional file 3. An overview of studies that report on comparison to a control group [37, 39, 40, 44, 45, 47-56, 58-61, 64, 67, 69-71] or distinguish between subgroups within the cerebral palsy (i.e. dyskinetic versus spastic) [38-40, 42, 51, 53, 55, 57, 66,83 ] are provided in Additional file 4. In four studies a reliability assessment was performed, either intra-session $[53,66]$ and /or test-retest reliability [61, 62, 66] (Additional file 5). Only one article used adequate statistical testing to determine reliability of the assessment, i.e. reporting intraclass correlation coefficients (ICC) and a measurement error [61]. Limitations of the remaining studies were that correlation coefficients were provided without testing for a systematic change between sessions [53], the number of subjects used for the reliability analysis were extremely low $(n=3)[62,66]$, or analyses were performed for the entire group of participants with $\mathrm{CP}$, without making a distinction for dyskinetic CP [53]. Additional file 6 provides an overview of studies used an instrumented method assessing the effects of an intervention (e.g. physical exercise [43], biofeedback [47, 64, 71, 76] splints [57], deep brain stimulation [62], botulinum Toxin Type B [63], different seating types [66, 80] and transcranial direct current stimulation [72-74].

\section{Discussion}

The current review provides an overview of available instrumented measurements to assess motor function in dyskinetic CP, at all levels of the ICF-CY. It can serve researchers and clinicians to make an informed decision about instrumented measurements in dyskinetic CP for their specific purpose. There is a range of instrumented methods to assess motor function in dyskinetic CP, especially for the upper extremity. Most methods assess voluntary movement expressed as spatiotemporal and kinematic parameters and involuntary movements expressed as overflow of muscle activation that is not directly required for a task.

\section{Muscle functions (muscle power, muscle tone / motor reflex, muscle endurance)}

Concerning muscle function, the majority of articles focused on muscle tone and motor reflex. Force and/or sEMG was measured during rest and movement (passive and active; slow and fast velocities) [36-38, 44, 46, 51]. Torques, force levels and force variability were described in two articles and classified within the ICF-CY level of functioning of muscle power $[38,45]$. No instrumented method is available to assess muscle endurance in dyskinetic CP. This is surprising since force generation and sustaining muscle contraction for a certain amount of 
time have an effect on task performance. It would be especially useful to assess muscle strength and power in children with dyskinetic $\mathrm{CP}$, because they present with lower maximal isometric flexion and extension torques in the lower limbs when compared to those with spasticity and typically developing children [38]. In addition to a severely impaired strength, children with dyskinetic $\mathrm{CP}$ showed increased force variability [45]. Thus strength measurements could provide important information concerning muscle function in dyskinetic CP.

\section{Movement functions (control of voluntary movement, involuntary movement, gait pattern)}

On the ICF level of functioning, control of voluntary movement was frequently assessed by analyzing muscle activity during different tasks via sEMG analyses [44, 59, $65,75,76]$. The average of co-contraction [59] and the relative contribution of muscle activity (task correlation index) $[75,76]$ during a repetitive task are possibly interesting variables to assess in children and young adults with dyskinetic CP. Yet experiments were performed in a small group and further development of methods would be necessary. Other ways to study control of voluntary movement were virtual reality or tracking games with various types of input systems (e.g. sEMG controlled input, a touch screen tablet or head mice). Assessment of tracking error, timing error, movement time, or speed-accuracy using Fitt's law were frequently employed [47, 49, 50, 64-67, 69-71, 73, 74, 77]. These studies point out that available software (e.g. FittsLawSoftware [85]), assessing point-and-click or drag and drop using the individual computer input device of a participant, could be an interesting option for assessment of control of voluntary movement as part of human-computer interaction in dyskinetic $\mathrm{CP}$.

Gait analysis and upper limb measurements using 3D motion capture systems and sEMG are frequently performed in the general population of $\mathrm{CP}$ and several recommendations and protocols are available for measurements of kinematics, including Vicon clinical manager or Plug in gait full body model (Vicon UK), American Society of Biomechanics recommendations for upper extremity motion analysis [86], University of Western Australia's (UWA) upper limb model [87], upper limb model proposed by Rab et al. [88], upper limb three-dimensional movement analysis (UL-3DMA) [89], ELEPAP clinical protocol [90-92] and Reach \& Grasp Cycle [93]. These recommendations and protocols were (partly) used in several of the reviewed articles [38-41, 53, 55-57, 60, 61]. Parameters that were mostly used to assess dyskinetic movements during gait and upper extremity tasks included variability and timing of movement trajectories, jerk, kinematic overflow and overflow measured by sEMG [39, 42, 44, 53, 54, 57, 58,
60, 61, 71, 73, 74]. Some of these parameters have already been shown to have a strong correlation to clinical comparator instruments $(r>0.70)$ (e.g. variability of ankle trajectory during swing [39], kinematic overflow $[51,60,61]$ number of movement units (i.e. acceleration-deacceleration) [52] and movement, reach or hold time [52, 55] (see Additional file 3) and might be interesting for assessment of treatment effects. For that, the reliability including measurement error is important to know, especially the test-retest reliability over different days. An insufficient reliability of assessment instruments can hamper results of clinical trials aiming to assess the efficacy of (new) treatments, if changes due to the intervention are not detected. Two studies assessed reliability of outcome variables but the reliability measurements were performed on the same day [53, 61]. Of these two studies, only one used adequate statistical testing following the COSMIN checklist of bias [61]. We expect that the variability of dyskinetic movements negatively affects test-retest reliability on different days, resulting in a higher measurement error in gait analysis and upper limb measurements for dyskinetic $\mathrm{CP}$ compared to the general population of $\mathrm{CP}$. To overcome this limitation measuring for a longer period of time might be necessary in dyskinetic $\mathrm{CP}$.

\section{Assessment of motor function in severely impaired children}

The majority of the reviewed methods have in common that they assessed muscle function and movement during tasks that require some level of understanding of a task instruction, manual ability and/or ambulation. However, it is known that in dyskinetic CP a high percentage of children has severe intellectual disability (about 70\%), severe visual impairments (about 40\%), and $70-80 \%$ are non-ambulatory (GMFCS IV-V) and have a severely impaired manual ability (MACS IV-V) [8, 9]. Therefore for a large group of children and young adults with dyskinetic $\mathrm{CP}$, only few instrumented methods are available. No task performance was required for assessing motor activity during rest with an accelerometer attached to the wrist [62] and for evaluation of seating using 3D motion capture and a pressure measurement system of the back, using an external perturbation by sudden noise to trigger dystonic movements [80]. Other possible options for the more severely impaired group are: assessment of head movement during computer use with a computer interface controlled by head movement (e.g. camera mouse, inertial sensor) [81, 82] or finger movement (e.g. wearable switch) [84] and assessment of movement and muscle function during very simple tasks i.e. operate a touch activated switch, perform an outward-reaching, a finger-to nose task, finger-tapping or eye blinking [59, 61, 63, 65-67, 79]. In summary, 
instrumented assessment for the severely impaired children and young adults are highly needed.

\section{Implications and future directions}

Using instrumented methods with a hypothesis about pathophysiological aspects in mind may lead to more understanding of the mechanisms behind current treatment and may possibly lead to new treatments or improvement of current treatments. It has been suggested that an imbalance between the direct and indirect pathway of the basal ganglia plays a role in how the brain lesion in dyskinetic $\mathrm{CP}$ effects movements (i.e. the direct pathway is responsible for the control of voluntary movement and the indirect pathway for the inhibition of involuntary movements) [4, 94]. Therefore the assessment methods of control of voluntary movements versus inhibition of involuntary movements or a combination thereof might help to gain more knowledge how brain abnormalities result in dystonia and choreoathetosis in dyskinetic CP.

Some articles of the current review could be classified within ICF-CY level of activities and participation. However, none of the methods actually assessed activities within the daily environment of the participants. Therefore it is questionable whether results can be generalized to real-life situations. A large number of children and young adults with dyskinetic $\mathrm{CP}$ are dependent on wheeled mobility (manual or powered), instrumented assessment of quality and quantity of wheelchair use might be worthwhile. Assessing the performance of wheeled mobility (or the performance of different control devices for powered wheeled mobility) within a virtual environment as recently reported [68] is a very interesting option for this group.

In the recent years wearable sensor techniques have increasingly been used for detecting specific movements of interest, e.g. stereotypical movement patterns in epilepsies as well as for activity monitoring in neurological disorders [95] including the general population of $\mathrm{CP}$ [96, 97]. However, no study was found specifically for dyskinetic CP. Wearable sensors might offer opportunities in monitoring dyskinetic movements outside the laboratory setting. Considering that severity of abnormal movements varies over time and is exacerbated by external stimuli, such as stress, pain, and noise [4], measuring during a longer period of time in the daily environment of children and young adults with dyskinetic CP might result in more reliable measures.

\section{Conclusion}

Although this current review shows the potential of several instrumented methods to be used as objective outcome measures in dyskinetic $\mathrm{CP}$, their methodological quality is still unknown. Future development should focus on evaluating their clinimetrics, including validating against clinical meaningfulness. New technological developments should aim for measurements that can be applied outside the laboratory. This is especially important for the group of severely impaired children and young adults with dyskinetic $\mathrm{CP}$.

\section{Supplementary information}

Supplementary information accompanies this paper at https://doi.org/10. 1186/s12984-020-00658-6.

Additional file 1. Search strategy.

Additional file 2. Overview of all included studies.

Additional file 3. Overview of studies that report correlation of parameters to a clinical comparator instrument.

Additional file 4. Overview of studies that report on comparison to a control group or distinguish between subgroups within the cerebral palsy (i.e. dyskinetic versus spastic).

Additional file 5. Overview of studies that report on reliability assessment.

Additional file 6. Overview of studies that report on pre/post intervention.

Additional file 7: Table S3. Characteristics of included studies (assessed body region, assessed ICF-CY categories, used instruments and technologies and measured parameters).

\section{Abbreviations}

BADS: Barry-Albright dystonia scale; BFMDRS: Burke-Fahn-Marsden dystonia rating scale; COPM: Canadian occupational performance measure; COSMIN: COnsensus-based Standards for the selection of health Measurement INstruments; CP: Cerbral palsy; CPCHILD: Child health index of life with disabilities; DIS: Dyskinesia impairment scale; GAS: Goal attainment scaling; GMFCS: Gross motor functioning classification system;

HAT: Hypertonia assessment tool; ICC: Intraclass correlation coefficient; ICF-

$\mathrm{CY}$ : International classification of functioning, disability and health for children and youth; MACS: Manual ability classification system; PEDI: Pediatric evaluation of disability inventory; PICOS: Participants, intervention, comparison, outcome, study design; PRISMA: Preferred reporting items for systematic reviews and meta-analyses; QUEST: Quality of upper extremity skills test; sEMG: surface electromyography; UDRS: Unified dystonia rating scale

\section{Acknowledgements}

Not applicable.

\section{Authors' contributions}

All authors were involved in the conception and design of the review, including the review protocol. The search was performed by EJ and $\mathrm{HH}$. Selection and data extraction were done by $H H$ and $M G$, with $L B$ and $A B$ as third and fourth reviewer in case of discussions. $\mathrm{HH}$ interpreted the data and wrote the first draft. All authors were involved in revising the draft and the final manuscript has been approved by all authors.

\section{Funding}

This review was performed as part of a project funded by the Phelps Stichting voor Spastici (2011037), het Revalidatiefonds (R2011032), Kinderrevalidatie Fonds de Adriaanstichting (11.02.17-2011/0035), and het Johanna KinderFonds (2011/0035-357). HH was supported by an Innovation Call of the Amsterdam Movement Sciences and MG by the Dutch Organization for Scientific Research (NWO) VIDlgrant (no. 016.156.346 FirSTeps).

\section{Availability of data and materials}

All data generated or analyzed during this study are included in this published article and its supplementary information files. 


\section{Ethics approval and consent to participate}

Not applicable.

\section{Consent for publication}

Not applicable.

\section{Competing interests}

The authors declare that they have no competing interests.

\section{Author details \\ 'Department of Rehabilitation Medicine, Amsterdam Movement Sciences, Amsterdam UMC, PO Box 7057, Amsterdam 1007MB, The Netherlands. ${ }^{2}$ Department of Human Movement Sciences, Faculty of Behavioural and Movement Sciences, Vrije Universiteit Amsterdam, Amsterdam Movement Sciences, Amsterdam, The Netherlands. ${ }^{3}$ Medical Library, Vrije Universiteit Amsterdam, Amsterdam, The Netherlands. ${ }^{4}$ Department of Epidemiology and Biostatistics, Amsterdam Public Health research institute, Amsterdam UMC, Location VUmc, Amsterdam, The Netherlands. ${ }^{5}$ Department of Biomechanical Engineering, Delft University of Technology, Delft, The Netherlands. ${ }^{6}$ Department of Neurology, Section of Pediatric Neurology, Maastricht UMC+, Maastricht, The Netherlands.}

\section{Received: 19 June 2019 Accepted: 13 February 2020}

Published online: 05 March 2020

\section{References}

1. SCPE. Prevalence and characteristics of children with cerebral palsy in Europe. Dev Med Child Neurol. 2002;44(9):633-40.

2. Himmelmann K, McManus V, Hagberg G, Uvebrant P, Krägeloh-Mann I, Cans C, et al. Dyskinetic cerebral palsy in Europe: trends in prevalence and severity. Arch Dis Child. 2009;94:921-6.

3. Graham HK, Rosenbaum P, Paneth N, Dan B, Lin JP, Damiano DL, et al. Cerebral palsy. Nat Rev Dis Primers. 2016;2:1-24.

4. Monbaliu E, Himmelman K, Lin JP, Ortibus E, Bonouvrié L, Feys H, et al. Clinical presentation and management of dyskinetic cerebral palsy. Lancet Neurol. 2017:16(9):741-9.

5. Monbaliu E, De Cock P, Mailleux L, Dan B, Feys H. The relationship of dystonia and choreoathetosis with activity, participation and quality of life in children and youth with dyskinetic cerebral palsy. Eur J Paediatr Neurol. 2017;21(2):327-35.

6. Palisano RJ, Rosenbaum P, Bartlett D, Livingston MH. Content validity of the expanded and revised gross motor function classification system. Dev Med Child Neurol. 2008:50(10):744-50.

7. Eliasson AC, Krumlinde-Sundholm L, Rösblad B, Beckung E, Arner M, Ohrvall AM, et al. The manual ability classification system (MACS) for children with cerebral palsy: scale development and evidence of validity and reliability. Dev Med Child Neurol. 2006:48(7):549-54.

8. Carnahan KD, Arner M, Hagglund G. Association between gross motor function (GMFCS) and manual ability (MACS) in children with cerebral palsy. A population-based study of 359 children. BMC Musculoskelet Disord. 2007;8:50.

9. Preel M, Rackauskaite G, Larsen ML, Laursen B, Lorentzen J, Born AP, et al. Children with dyskinetic cerebral palsy are severely affected as compared to bilateral spastic cerebral palsy. Acta Paediatr. 2019;108(10):1850-6.

10. Stewart K, Harvey A, Johnston LM. A systematic review of scales to measure dystonia and choreoathetosis in children with dyskinetic cerebral palsy. Dev Med Child Neurol. 2017;59(8):786-95.

11. Barry MJ, VanSwearingen JM, Albright AL. Reliability and responsiveness of the Barry-Albright Dystonia scale. Dev Med Child Neurol. 1999:41(6):404-11.

12. Monbaliu E, Ortibus E, de Cat J, Dan B, Heyrman L, Prinzie P, et al. The dyskinesia impairment scale: a new instrument to measure dystonia and choreoathetosis in dyskinetic cerebral palsy. Dev Med Child Neurol. 2012;54: 278-83.

13. Burke RE, Fahn S, Marsden CD, Bressman SB, Moskowitz C, Friedman J. Validity and reliability of a rating scale for the primary torsion dystonias. Neurology. 1985;35(1):73-7.

14. Knights S, Datoo N, Kawamura A, Switzer L, Fehlings D. Further evaluation of the scoring, reliability, and validity of the hypertonia assessment tool (HAT). J Child Neurol. 2014;29(4):500-4.

15. Marsico P, Frontzek-Weps V, Balzer J, van Hedel HJ. Hypertonia assessment tool. J Child Neurol. 2017;32(1):132-8.
16. Comella CL, Leurgans S, Wuu J, Stebbins GT, Chmura T, Dystonia SG. Rating scales for dystonia: a multicenter assessment. Mov Disord. 2003:18(3):303-12

17. Haley SM, Coster WJ, Ludlow LH, Haltiwanger JT, Andrellos PJ. Pediatric evaluation of disability inventory (PEDI): development standardization and administration manual. Boston: New England Medical Center; 1992.

18. Narayanan UG, Fehlings D, Weir S, Knights S, Kiran S, Campbell K. Initial development and validation of the caregiver priorities and child health index of life with disabilities (CPCHILD). Dev Med Child Neurol. 2006;48(10):804-12.

19. Thorley M, Lannin N, Cusick A, Novak I, Boyd R. Construct validity of the quality of upper extremity skills test for children with cerebral palsy. Dev Med Child Neurol. 2012;54(11):1037-43.

20. Turner-Stokes L. Goal attainment scaling (GAS) in rehabilitation: a practical guide. Clin Rehabil. 2009;23:362-70.

21. Law M, Baptiste S, McColl M, Opzoomer A, Polatajko H, Pollock N. The Canadian occupational performance measure: an outcome measure for occupational therapy. Can J Occup Ther. 1990;57(2):82-7.

22. Stewart K, Hutana G, Kentish M. Intrathecal baclofen therapy in paediatrics: a study protocol for an Australian multicentre, 10-year prospective audit. BMJ Open. 2017:7(6):e015863.

23. Bonouvrié LA, Becher JG, Vles JSH, Boeschoten K, Soudant D, de Groot V, et al. Intrathecal baclofen treatment in dystonic cerebral palsy: a randomized clinical trial: the IDYS trial. BMC Pediatr. 2013;131:175-83.

24. Eek MN, Olsson K, Lindh K, Askljung B, Pahlman M, Corneliusson O, et al. Intrathecal baclofen in dyskinetic cerebral palsy: effects on function and activity. Dev Med Child Neurol. 2018;60(1):94-9.

25. Elia AE, Bagella C, Ferre F, Zorzi G, Calandrella D, Romito LM. Deep brain stimulation for dystonia due to cerebral palsy: a review. Eur J Paediatr Neurol. 2018:22·308-15.

26. Masson R, Pagliano E, Baranello G. Efficacy of oral pharmaccological treatments in dyskinetic cerebral palsy: a systematic review. Dev Med Child Neurol. 2017:59:1237-48.

27. Gimeno H, Tustin K, Lumsden D, Ashkan K, Selway R, Lin JP. Evaluation of functional goal outcomes using the Canadian occupational performance measure (COPM) following deep brain stimulation (DBS) in childhood dystonia. Eur J Paediatr Neurol. 2014;18(3):308-16.

28. Bonouvrie LA, Becher JG, Vles JSH, Vermeulen RJ, Buizer Al, Group IS. The effect of Intrathecal baclofen in Dyskinetic cerebral palsy: the IDYS trial. Ann Neurol. 2019;86(1):79-90.

29. Pavone L, Burton J, Gaebler-Spira D. Dystonia in childhood: clinical and objective measures and functional implications. J Child Neurol. 2013;28(3):340-50.

30. WHO. International Classification of Functioning, Disability and Health (ICF). Geneva: Organization WH; 2001.

31. WHO. International classification of functioning, disability and health: children \& youth version: ICF-CY. 2007.

32. Haberfehlner H, Buizer Al, Goudriaan M, Harlaar J, van der Krogt MM, Vermeulen RJ, Bonouvrié LA, Jansma EP. Objective assessment of movement disorders in dyskinetic cerebral palsy. PROSPERO 2018 CRD42018106165 Available from: https://www.crd.york.ac.uk/prospero/ display record.php?|D=CRD42018106165.

33. Ouzzani M, Hammady H, Fedorowicz Z, Elmagarmid A. Rayyan-a web and mobile app for systematic reviews. Syst Rev. `2016:5(1):210.

34. Moher D, Liberati A, Tetzlaff J, Altman DG, Group P. Preferred reporting items for systematic reviews and meta-analyses: the PRISMA statement. PLoS Med. 2009;6(7):e1000097.

35. Mokkink LB, de Vet HCW, Prinsen CAC, Patrick DL, Alonso J, Bouter LM, et al. COSMIN risk of Bias checklist for systematic reviews of patient-reported outcome measures. Qual Life Res. 2018;27(5):1171-9.

36. Androwis GJ, Michael PA, Jewaid D, Nolan KJ, Strongwater A, Foulds RA. Motor control investigation of dystonic cerebral palsy: a pilot study of passive knee trajectory. Conf Proc IEEE Eng Med Biol Soc. 2015;2015:4562-5.

37. Beattie C, Gormley M, Wervey R, Wendorf H. An electromyographic protocol that distinguishes spasticity from dystonia. J Pediatr Rehabil Med. 2016;9(2):125-32.

38. Lebiedowska MK, Gaebler-Spira D, Burns RS, Fisk JR. Biomechanic characteristics of patients with spastic and dystonic hypertonia in cerebral palsy. Arch Phys Med Rehabil. 2004;85(6):875-80

39. Abel R, Rupp R, Sutherland D. Quantifying the variability of a complex motor task specifically studying the gait of dyskinetic CP children. Gait Posture. 2003:17(1):50-8.

40. Davids JR, Foti T, Dabelstein J, Blackhurst DW, Bagley A. Objective assessment of dyskinesia in children with cerebral palsy. J Pediatr Orthop. 1999:19(2):211-4. 
41. Petrarca M, Favetta M, Romano A, Castelli E. Case report: atypical gait pattern in a child with dystonic CP. Gait Posture. 2017;57:335.

42. Sangeux M, Robinson L, Graham K. Objective measurement of dystonia during gait from kinematics variability. Dev Med Child Neurol. 2016;58:18.

43. Berg K, Kadefors R, Petersen I. Effect of muscular exhaustion on myo-electric functions in adolescents with athetosis and or dystonia. Scand J Rehabil Med. 1969; 1(3):143-6.

44. Kukke SN, Sanger TD. Contributors to excess antagonist activity during movement in children with secondary dystonia due to cerebral palsy. J Neurophysiol. 2011;105(5):2100-7.

45. Chu WT, Sanger TD. Force variability during isometric biceps contraction in children with secondary dystonia due to cerebral palsy. Mov Disord. 2009; 24(9):1299-305.

46. van Doornik J, Kukke S, Sanger TD. Hypertonia in childhood secondary dystonia due to cerebral palsy is associated with reflex muscle activation. Mov Disord. 2009;24(7):965-71.

47. Young SJ, van Doornik J, Sanger TD. Visual feedback reduces co-contraction in children with dystonia. J Child Neurol. 2011;26(1):37-43.

48. Niku S, Henderson JM. Toward quantification of athetotic movements by frequency spectrum analysis. J Biomech. 1985;18(1):71-6.

49. Chu WW, Sternad D, Sanger TD. Healthy and dystonic children compensate for changes in motor variability. J Neurophysiol. 2013;109(8):2169-78.

50. Chu W, Park SW, Sanger TD, Sternad D. Children with Dystonia can learn a novel motor skill: strategies that are tolerant to high variability. IEEE Trans Neural Syst Rehabil Eng. 2016;24(8):847-58.

51. Gordon LM, Keller JL, Stashinko EE, Hoon AH, Bastian AJ. Can spasticity and dystonia be independently measured in cerebral palsy? Pediatr Neurol. 2006;35(6):375-81.

52. Butler EE, Ladd AL, Lamont LE, Rose J. Temporal-spatial parameters of the upper limb during a Reach \& Grasp Cycle for children. Gait Posture. 2010;32(3):301-6.

53. Butler $\mathrm{EE}$, Rose J. The pediatric upper limb motion index and a temporalspatial logistic regression: quantitative analysis of upper limb movement disorders during the Reach \& Grasp Cycle. J Biomech. 2012;45(6):945-51.

54. Damiano DL, Shah S, Stanley CJ, Alter KE. Quantifying bilateral motor deficits in childhood onset hemidystonia. Dev Med Child Neurol. 2010;52:7.

55. de Campos AC, Kukke SN, Hallett M, Alter KE, Damiano DL. Characteristics of bilateral hand function in individuals with unilateral dystonia due to perinatal stroke: sensory and motor aspects. J Child Neurol. 2014;29(5):623-32.

56. Kukke SN, Curatalo LA, de Campos AC, Hallett M, Alter KE, Damiano DL. Coordination of reach-to-grasp kinematics in individuals with childhoodonset Dystonia due to hemiplegic cerebral palsy. IEEE Trans Neural Syst Rehabil Eng. 2016;24(5):582-90.

57. Elliott C, Reid S, Hamer P, Alderson J, Elliott B. Lycra((R)) arm splints improve movement fluency in children with cerebral palsy. Gait Posture. 2011;33(2):214-9.

58. Sanger TD. Arm trajectories in dyskinetic cerebral palsy have increased random variability. J Child Neurol. 2006;21 (7):551-7.

59. Malfait N, Sanger TD. Does dystonia always include co-contraction? A study of unconstrained reaching in children with primary and secondary dystonia. Exp Brain Res. 2007;176(2):206-16.

60. Pons R, Vanezis A, Skouteli H, Papavasiliou A, Tziomaki M, Syrengelas D, et al. Upper limb function, kinematic analysis, and Dystonia assessment in children with spastic Diplegic cerebral palsy and periventricular Leukomalacia. J Child Neurol. 2017;32(11):936-41.

61. Kawamura A, Klejman S, Fehlings D. Reliability and validity of the kinematic dystonia measure for children with upper extremity dystonia. J Child Neurol. 2012;27(7):907-13.

62. Legros A, Diakonova N, Cif L, Hemm S, Vayssiere N, Coubes P, et al. Accelerometric measurement of involuntary movements during pallidal deep brain stimulation of patients with generalized dystonia. Brain Res Bull. 2004;64(4):363-9.

63. Sanger TD, Kukke SN, Sherman-Levine S. Botulinum toxin type B improves the speed of reaching in children with cerebral palsy and arm dystonia: an open-label, dose-escalation pilot study. J Child Neurol. 2007;22(1):116-22.

64. Liyanagamage SA, Bertucco M, Bhanpuri NH, Sanger TD. Scaled vibratory feedback can Bias muscle use in children with Dystonia during a redundant, 1-dimensional Myocontrol task. J Child Neurol. 2017;32(2):161-9.

65. Nwaobi OM. Nondominant arm restraint and dominant arm function in a child with athetoid cerebral palsy: electromyographic and functional evaluation. Arch Phys Med Rehabil. 1987;68(12):837-9.

66. Nwaobi OM. Seating orientations and upper extremity function in children with cerebral palsy. Phys Ther. 1987;67(8):1209-12.
67. Sanger TD, Kaiser J, Placek B. Reaching movements in childhood dystonia contain signal-dependent noise. J Child Neurol. 2005;20(6):489-96.

68. Rabhi Y, Mrabet M, Fnaiech F. Intelligent control wheelchair using a new visual joystick. J Healthc Eng. 2018;2018:6083565.

69. Bertucco M, Sanger TD. Speed-accuracy testing on the apple iPad provides a quantitative test of upper extremity motor performance in children with dystonia. J Child Neurol. 2014;29(11):1460-6.

70. Bertucco M, Bhanpuri NH, Sanger TD. Perceived cost and intrinsic motor variability modulate the speed-accuracy trade-off. PLoS One. 2015;10(10): e0139988.

71. Young SJ, van Doornik J, Sanger TD. Finger muscle control in children with dystonia. Mov Disord. 2011;26(7):1290-6.

72. Young SJ, Bertucco M, Sheehan-Stross R, Sanger TD. Cathodal transcranial direct current stimulation in children with dystonia: a pilot open-label trial. J Child Neurol. 2013:28(10):1238-44.

73. Young SJ, Bertucco M, Sanger TD. Cathodal transcranial direct current stimulation in children with dystonia: a sham-controlled study. J Child Neurol. 2014;29(2):232-9.

74. Bhanpuri NH, Bertucco M, Young SJ, Lee AA, Sanger TD. Multiday Transcranial direct current stimulation causes clinically insignificant changes in childhood Dystonia: a pilot study. J Child Neurol. 2015;30(12):1604-15.

75. Lunardini F, Cesareo A, Biffi E, Casellato C, Pedrocchi A, Sanger TD. EMGbased vibro-tactile biofeedback improves motor control in children with secondary dystonia: two case reports. Neuropsychiatry. 2016;6(6):337-43.

76. Bertucco M, Lunardini F, Nardon M, Casellato C, Pedrocchi A, Sanger T, editors. Vibro-tactile EMG-based biofeedback induces changes of muscle activity patterns in childhood dystonia. 2019 9th International IEEE/EMBS Conference on Neural Engineering (NER); 2019 20-23 March 2019.

77. Choi KS, Lo KH. A hand rehabilitation system with force feedback for children with cerebral palsy: two case studies. Disabil Rehabil. 2011;33(17): 1704-14.

78. Nicholson JH, Morton RE, Attfield S, Rennie D. Assessment of upper-limb function and movement in children with cerebral palsy wearing lycra garments. Dev Med Child Neurol. 2001;43(6):384-91.

79. Garavaglia L, Pagliano E, Arnoldi MT, LoMauro A, Zanin R, Baranello G, et al. Two single cases treated by a new pseudoelastic upper-limb orthosis for secondary dystonia of the young. IEEE Int Conf Rehabil Robot. 2017;2017: $1260-5$.

80. Cimolin V, Piccinini L, Avellis M, Cazzaniga A, Turconi AC, Crivellini M, et al. 3D-quantitative evaluation of a rigid seating system and dynamic seating system using 3D movement analysis in individuals with dystonic tetraparesis. Disabil Rehabil Assist Technol. 2009;4(6):422-8.

81. Man DW, Wong MS. Evaluation of computer-access solutions for students with quadriplegic athetoid cerebral palsy. Am J Occup Ther. 2007:61(3):355-64.

82. Raya R, Ceres R, Roa JO, Rocon E. Assessment of the involuntary motion of children with motor impairments to improve the accessibility of an inertial interface. Proceedings of IDC2010: The 9th International Conference on Interaction Design and Children; 2010. p. 128-37.

83. Saavedra S, Woollacott M, van Donkelaar P. Head stability during quiet sitting in children with cerebral palsy: effect of vision and trunk support. Exp Brain Res. 2010;201(1):13-23.

84. Yamamoto A, Kihara K, Yagi M, Matsumoto Y, Tsuneishi S, Otaka H, et al. Application of a wearable switch to perform a mouse left click for a child with mix type of cerebral palsy: a single case study. Disabil Rehabil Assist Technol. 2019;2020;15(1):54-9.

85. MacKenzie IS. Retrieved June 19, 2019, from http://www.yorku.ca/mack/ FittsLawSoftware

86. Wu G, van der Helm FC, Veeger HE, Makhsous M, Van Roy P, Anglin C, et al. ISB recommendation on definitions of joint coordinate systems of various joints for the reporting of human joint motion--part ll: shoulder, elbow, wrist and hand. J Biomech. 2005;38(5):981-92.

87. Reid S, Elliott C, Alderson J, Lloyd D, Elliott B. Repeatability of upper limb kinematics for children with and without cerebral palsy. Gait Posture. 2010; 32(1):10-7.

88. Rab G, Petuskey K, Bagley A. A method for determination of upper extremity kinematics. Gait Posture. 2002;15(2):113-9.

89. Jaspers E, Feys H, Bruyninckx H, Cutti A, Harlaar J, Molenaers G, et al. The reliability of upper limb kinematics in children with hemiplegic cerebral palsy. Gait Posture. 2011;33(4):568-75.

90. Feng CJ, Mak AF. Three-dimensional motion analysis of the voluntary elbow movement in subjects with spasticity. IEEE Trans Rehabil Eng. 1997;5(3):253-62. 
91. Menegoni F, Milano E, Trotti C, Galli M, Bigoni M, Baudo S, et al.

Quantitative evaluation of functional limitation of upper limb movements in subjects affected by ataxia. Eur J Neurol. 2009;16(2):232-9.

92. Vanezis A, Robinson MA, Darras $\mathrm{N}$. The reliability of the ELEPAP clinical protocol for the 3D kinematic evaluation of upper limb function. Gait Posture. 2015:41(2):431-9.

93. Butler EE, Ladd AL, Louie SA, Lamont LE, Wong W, Rose J. Threedimensional kinematics of the upper limb during a reach and grasp cycle for children. Gait Posture. 2010;32(1):72-7.

94. Hallett M. Neurophysiology of dystonia: the role of inhibition. Neurobiol Dis. 2011:42(2):177-84.

95. Johansson D, Malmgren K, Alt MM. Wearable sensors for clinical applications in epilepsy, Parkinson's disease, and stroke: a mixed-methods systematic review. J Neurol. 2018;265(8):1740-52.

96. Ahmadi M, O'Neil M, Fragala-Pinkham M, Lennon N, Trost S. Machine learning algorithms for activity recognition in ambulant children and adolescents with cerebral palsy. J Neuroeng Rehabil. 2018;15(1):105.

97. Mitchell LE, Ziviani J, Oftedal S, Boyd RN. A systematic review of the clinimetric properties of measures of habitual physical activity in primary school aged children with cerebral palsy. Res Dev Disabil. 2013;34(8):2419-32.

\section{Publisher's Note}

Springer Nature remains neutral with regard to jurisdictional claims in published maps and institutional affiliations.

Ready to submit your research? Choose BMC and benefit from:

- fast, convenient online submission

- thorough peer review by experienced researchers in your field

- rapid publication on acceptance

- support for research data, including large and complex data types

- gold Open Access which fosters wider collaboration and increased citations

- maximum visibility for your research: over $100 \mathrm{M}$ website views per year

At BMC, research is always in progress.

Learn more biomedcentral.com/submissions 